\title{
FOREWORD
}

\section{Endoscopy: a clinical state of the art}

\author{
G.M. Verleden*, C. Dooms*, M. Noppen ${ }^{\#}$ and M. Decramer*
}

An introduction to a series of articles on clinical state-of-the-art endoscopy

E ndoscopy has been used for a long time in pulmonary diseases departments all over the world, but in recent years a lot of new ideas have become available regarding the role of thoracoscopy for the pulmonologist, not only for diagnosis but also concerning treatment. Furthermore, new diagnostic bronchoscopy techniques are now in use, which are especially interesting in the staging of mediastinal lymph nodes and further diagnosis of peripheral lesions in the lung.

The purpose of the international symposium "Endoscopy: a clinical state of the art", organised by the Dept of Respiratory Diseases, University Hospital Gasthuisberg at the Katholieke Universiteit, Leuven, Belgium on March 19-21, 2009, was to provide a clinical update of several issues regarding endoscopic diagnosis and treatment. Various clinical and basic researchers and internationally renowned experts in the field were brought together from all over Europe to discuss these issues, which are the subject of the current issue of the ERR.

In the first review of this series, JANSSEN [1] discusses the diagnostic and therapeutic aspects of thoracoscopy in patients with pleural effusions. The second paper by NOPPEN [2] deals with the epidemiology, pathophysiology and different causes of spontaneous pneumothorax. In the third chapter, BRIMS et al. [3] describe new insights into empyema thoracis, with special emphasis on its aetiology, diagnosis and treatment. The next paper deals with the current role of bronchoscopy, and goes into more detail about the role of autofluorescence bronchoscopy and endoscopic ultrasound [4]. In the fifth review, WELLS [5] describes the clinical utility of bronchoalveolar lavage in diffuse parenchymal lung diseases, and in the final paper VAN RAEMDONCK and NiNANE [6] make a plea for surgical versus endoscopic lung volume reduction.

We do hope that this issue of the European Respiratory Review will provide an interesting synthesis and update of the current knowledge on different aspects of endoscopy in pulmonary diseases.

\section{STATEMENT OF INTEREST}

None declared.

\section{ACKNOWLEDGEMENTS}

The authors would like to thank M. Humbert, (Hôpital Antoine Béclère, Clamart, France) for granting them the privilege of publishing the international symposium "Endoscopy: a clinical state of the art" in the European Respiratory Review. The authors would especially like to thank the sponsors for allowing us to organise the international symposium in Leuven, Belgium and in particular GlaxoSmithKline, Belgium for the unrestricted grant for this publication.

\section{REFERENCES}

1 Janssen JP. Why you do or do not need thoracoscopy. Eur Respir Rev 2010; 19: 213-216.

2 Noppen M. Spontaneous pneumothorax: epidemiology, pathophysiology and cause. Eur Respir Rev 2010; 19: 217-219.

3 Brims FJH, Lansley SM, Waterer GW, et al. Empyema thoracis: new insights into an old disease. Eur Respir Rev 2010; 19: 220-228.

4 Dooms C, Seijo L, Gasparini S, et al. Diagnostic bronchoscopy: state of the art. Eur Respir Rev 2010; 19: 229-236.

5 Wells AU. The clinical utility of bronchoalveolar lavage in diffuse parenchymal lung disease. Eur Respir Rev 2010; 19: 237-241.

6 Van Raemdonck D, Ninane V. Lung volume reduction for severe emphysema: do we need a scalpel or a scope? Eur Respir Rev 2010; 19: 242-247.

\section{AFFILIATIONS}

${ }^{*}$ Dept of Respiratory Diseases, University Hospital Gasthuisberg Leuven, and

"Dept of Respiratory Diseases, University Hospital UZ Brussel, Brussels, Belgium.

CORRESPONDENCE

G.M. Verleden

Dept of Respiratory Diseases

University Hospital Gasthuisberg

49 Herestraat

B-3000 Leuven

Belgium

E-mail: geert.verleden@

uz.kuleuven.ac.be

Received:

May 252010

Accepted:

May 262010

PROVENANCE

Publication of this peer-reviewed article was supported by GlaxoSmithKline, Belgium (principal sponsor, European Respiratory

Review issue 117). 